\title{
Axl receptor tyrosine kinase is a novel target of apigenin for the inhibition of cell proliferation
}

\author{
KYUNG-CHAN KIM ${ }^{1}$, EUN-HA CHOI ${ }^{2}$ and CHUHEE LEE ${ }^{2}$ \\ ${ }^{1}$ Department of Internal Medicine, College of Medicine, Catholic University of Daegu, \\ Daegu 705-718; ${ }^{2}$ Department of Biochemistry and Molecular Biology, School of Medicine, \\ Yeungnam University, Daegu 705-717, Republic of Korea
}

Received February 6, 2014; Accepted June 3, 2014

DOI: $10.3892 / \mathrm{ijmm} .2014 .1804$

\begin{abstract}
The Axl receptor tyrosine kinase (RTK), along with Tyro 3 and Mer, belongs to the TAM subfamily that promotes survival, stimulates proliferation and/or inhibits apoptosis. In various types of human cancer, including breast, lung and prostate cancer, Axl expression is increased and correlates with an advanced clinical stage. In this study, we examined whether apigenin has an effect on Axl expression, which in turn can affect cell proliferation. The treatment of the non-small cell lung cancer (NSCLC) cells, A549 and H460, with apigenin decreased Axl mRNA and protein expression in a dose-dependent manner. Axl promoter activity was also inhibited by apigenin, indicating that apigenin suppressed Axl expression at the transcriptional level. Upon treatment with apigenin, the viability of both the A549 and H460 cells was gradually decreased and the anti-proliferative effects were further confirmed by the dose-dependent decrease in the clonogenic ability of the apigenin-treated cells. Subsequently, we found that the viability and clonogenic ability of the cells treated with apigenin was less or more affected by transfection of the cells with a Axl-expressing plasmid or Axl targeting siRNA, compared to transfection with the empty vector or control siRNA, respectively. In addition, apigenin increased the expression of $\mathrm{p} 21$, a cyclin-dependent kinase inhibitor, but reduced the expression of X-linked inhibitor of apoptosis protein (XIAP). These cell cycle arrest and pro-apoptotic effects of apigenin were also attenuated or augmented by the up- or downregulation of Axl expression, respectively, which suggests that Axl is a novel target of apigenin through which it exerts its inhibitory effects on cell proliferation. Taken together, our data indicate that apigenin downregulates Axl expression, which subsequently results in the inhibition of NSCLC cell
\end{abstract}

Correspondence to: Dr Chuhee Lee, Department of Biochemistry and Molecular Biology, School of Medicine, Yeungnam University, 317-1 Daemyung-Dong, Daegu 705-717, Republic of Korea

E-mail: chlee2@ynu.ac.kr

Key words: apigenin, Axl, lung cancer, p21, X-linked inhibitor of apoptosis proliferation through the increase and decrease of p21 and XIAP expression, respectively.

\section{Introduction}

Apigenin (4',5,7,-tirhydoxyflavone) is a dietary flavone that is naturally found as a dimer, diapigenin (1), apigenin-7-O-glucoside or acetylated derivative (2). It is abundantly present in various fruits, plants, vegetables and some herbs (3-6). Plantderived beverages, including herbal tea and red wine, are good sources of apigenin (7). Apigenin has received significant attention as a preventive, as well as a therapeutic agent due to its efficacy and low intrinsic toxicity.

The effects of apigenin on growth inhibition, cell cycle arrest and the induction of apoptosis have been demonstrated in various types of cancer, such as breast cancer with high levels of HER2/neu (8), as well as cervical (8), lung (9), colon (10), hematologic (11) and ovarian cancer (12). In mouse models of prostate cancer, orally delivered apigenin has been shown to reduce tumor volume and suppress metastasis (13). The antiangiogenic property of apigenin has also been reported in lung (14), ovarian (15) and prostate cancer (16), which is the result of the transcriptional repression of vascular endonthelial growth factor expression through the downregulation of hypoxia-inducible factor (HIF)1- $\alpha$ expression levels.

In the human genome, 58 receptor tyrosine kinases (RTKs) are known to date; these are catagorized into 20 subfamilies and integrated into one large RTK family. Axl RTK, also known as Ark or Ufo, belongs to the TAM subfamily, which also contains Tyro 3 and Mer. It was initially identified in 1988 as an unidentified transforming gene (17) from chronic myelogenous leukemia patients and cloned in 1991 from primary human leukemia cells (18).

Axl has been shown to be overexpressed in various types of cancer, including acute leukemia (19), as well as breast (20), colon (21), thyroid (22), esophageal (23) and lung cancer (24). Enhanced Axl expression and activation through binding with its ligand, growth arrest-specific 6 (a vitamin K-dependent protein), has been shown to promote downstream signaling for cell proliferation and survival (25-27). Recently, Axl activation has also been identified as a novel mechanism that renders nonsmall cell lung cancer (NSCLC) cells and HER2/neu-positive breast cancer cells resistant to epidermal growth factor (EGF) 
RTK inhibitor (TKI) (28) and dual TKIs, such as lapatinib (29), respectively. Therefore, the inhibition of Axl expression and Axl-mediated signaling may be a potential therapeutic target for cancer treatment.

In this study, we examined the effects of apigenin on Axl expression and the subsequent effects on cell proliferation in human lung cancer cells. Apigenin was found to downregulate Axl expression, which resulted in the inhibition of cell proliferation through the induction of $\mathrm{p} 21$ protein expression and the suppression of the expression of X-linked inhibitor of apoptosis protein (XIAP).

\section{Materials and methods}

Reagents and antibodies. A549 and H460 cells were purchased from the American Type Culture Collection (Manassas, VA, USA). Apigenin was obtained from Sigma (St. Louis, MO, USA). Primers for Axl were synthesized by the domestic company, Bioneer Corp. (Daejeon, Korea). TRI reagent was obtained from Solgent Co., Ltd. (Daejeon, Korea). AmpliTaq DNA polymerase and Lipofectamine 2000 were obtained from Roche Diagnostics Corp. (Indianapolis, IN, USA) and Invitrogen (Carlsbad, CA, USA), respectively. G418 was from Gibco BRL (Gaithersburg, MD, USA). The plasmid, pGL3-basic vector, and the Dual-Glo luciferase assay kit were purchased from Promega Corp. (Madison, WI, USA). For western blot analysis, specific antibodies against Axl, p21, XIAP and GAPDH, as well as secondary antibodies were obtained from Santa Cruz Biotechnology (Dallas, TX, USA).

Cell culture. The A549 and H460 cells were grown in RPMI-1640 (Gibco BRL) containing 10\% FBS, 2 mM L-glutamine, $10 \mathrm{U} / \mathrm{ml}$ penicillin and $10 \mathrm{~g} / \mathrm{ml}$ streptomycin at $37^{\circ} \mathrm{C}$ in $5 \% \mathrm{CO}_{2}$ in a water-saturated atmosphere.

Reverse transcription PCR (RT-PCR) and quantitative PCR $(q P C R)$. The A549 and $\mathrm{H} 460$ cells $\left(1 \times 10^{6}\right)$ were seeded in a $100-\mathrm{mm}$ culture dish and grown overnight. The cells were then treated with the indicated concentrations $(0,10,20$ and $40 \mu \mathrm{M})$ of apigenin for $24 \mathrm{~h}$. Total RNA was extracted using TRI reagent and subjected to cDNA synthesis and PCR. The specific primers were as follows: Axl sense, 5'-AACCTTCAACTCC TGCCTTCTCG-3' and antisense,5'-CAGCTTCTCCTTCAGC TCTTCAC-3'; GAPDH sense, 5'-GGAGCCAAAAGGGTCAT CAT-3' and antisense, 5'-GTGATGGCATGGACTGTGGT-3'. To quantify the Axl mRNA levels in the A549 and H460 cells before and after treatment with apigenin, qPCR was performed using SYBR-Green PCR Master mix and the ABI PRISM 7900HT system (Applied Biosystems, Foster City, CA, USA). The mRNA level of Axl was normalized to that of GAPDH, using the $2^{-\triangle \triangle C T}$ method.

Western blot analysis. Total cell lysates were prepared from the A549 or H460 cells treated with the indicated concentrations $(0,10,20$ and $40 \mu \mathrm{M})$ of apigenin using lysis buffer [1\% Triton $\mathrm{X}-100,50 \mathrm{mM}$ Tris (pH 8.0), $150 \mathrm{mM} \mathrm{NaCl}$, $1 \mathrm{mM}$ PMSF, $1 \mathrm{mM} \mathrm{Na}_{3} \mathrm{VO}_{4}$, and protease inhibitor cocktail]. Untreated cells were used as controls. Protein concentrations were determined using Bio-Rad protein assays. Proteins from the cell lysates $(20-40 \mu \mathrm{g})$ were separated by $12 \%$ SDS-PAGE, and electrotransferred onto nitrocellulose membranes. The membranes were blocked for $30 \mathrm{~min}$ at room temperature in Tris-buffered saline with $0.05 \%$ Tween-20 (TTBS) containing $5 \%$ non-fat dry milk, and then incubated with TTBS containing a primary antibody for $4 \mathrm{~h}$ at room temperature. After $3 \times 10$ min washes in TTBS, the membranes were incubated with peroxidase-conjugated secondary antibody for $1 \mathrm{~h}$. Following 3 additional 10-min washes with TTBS, the protein bands of interest were visualized using an enhanced chemiluminescence detection system (Amersham ${ }^{\mathrm{TM}}$ ECL $^{\mathrm{TM}}$ Prime Western Blotting Detection Reagent; GE Healthcare, Piscataway, NJ, USA).

Clonogenic assay. The A549 or $\mathrm{H} 460$ cells were seeded in $35-\mathrm{mm}$ culture dishes $\left(2 \times 10^{3}\right.$ cells/dish) and cultured for the following 7-10 days under the indicated concentrations $(0,10$, 20 and $40 \mu \mathrm{M}$ ) of apigenin to form colonies. Colonies of $>50$ cells were stained with Crystal violet (in 60\% methanol; Junsei Chemical Co., Ltd., Tokyo, Japan) and images were acqired using the RAS-3000 Image Analysis System (FujiFilm, Tokyo, Japan).

Cell viability assay. The Cell Counting kit-8 (Dojindo Laboratories, Kumamoto, Japan) was used to measure the viability of the cells. Briefly, $1 \times 10^{3}$ cells were seeded in each well of 96-well plates and grown overnight at $37^{\circ} \mathrm{C}$ and then treated with the indicated concentrations $(0,10,20$ and $40 \mu \mathrm{M}$ ) of apigenin for $24 \mathrm{~h}$. At the end of treatment, $10 \mu \mathrm{l}$ of CCK-8 solution were added followed by incubation for a further $4 \mathrm{~h}$. The absorbance at $450 \mathrm{~nm}$ was measured using a microplate reader (Model 680 microplate reader; Bio-Rad Laboratories, Inc., Hercules, CA, USA). Values are the means \pm SD for triplicate wells and were normalized to those of the control group to determine the percentage viability.

Ectopic expression of Axl. To ectopically express Axl, the recombinant plasmid, pcDNA3-Axl, was constructed by cloning the Axl cDNA into the EcoRI and BamHI sites of the pcDNA3 vector and $2 \mu \mathrm{g}$ of purified plasmids were transfected into the A549 or $\mathrm{H} 460$ cells ( $3 \times 10^{5}$ cells in a $100-\mathrm{mm}$ dish) using Lipofectamine 2000 (Invitrogen). To establish stable cell lines, which constitutively express Axl, the transfected cells were cultured in the presence of $400 \mu \mathrm{g} / \mathrm{ml}$ of G418. The RPMI- 1640 medium containing G418 was refreshed every 3 days. After 3-4 weeks, the Axl-expressing cells were enriched and the Axl expression in these cells was analyzed by western blot analysis.

Promoter activity test. To construct pGL3-AXL, the Axl promoter region ranging from -887 to $+7 \mathrm{bp}$ of the transcriptional start site was amplified by PCR and subcloned into the pGL3-basic vector, the luciferase reporter plasmid. The constructed promoter-reporter plasmid was co-transfected into cells ( $3 \times 10^{5}$ cells in a $100 \mathrm{~mm}$ dish) with renilla luciferase vectors, pRL-SV40, as an internal control. Luciferase activity was measured using a Dual-Glo luciferase assay system.

siRNA trasnfection. To inhibit Axl expression, RNA interference (RNAi)-induced gene silencing was performed. The H460 cells $\left(1 \times 10^{6}\right)$ were seeded in a 100 -mm culture dish, grown overnight and then transfected with $50 \mathrm{nM}$ siRNA targeting Axl(sense, 5'-AAGAUUUGGAGAACACACUGA-3'; 
A
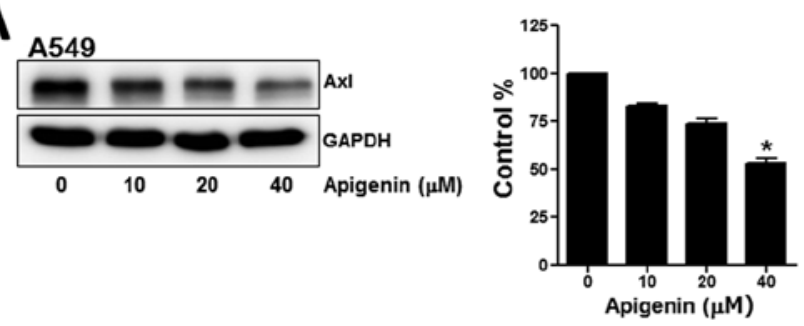

B
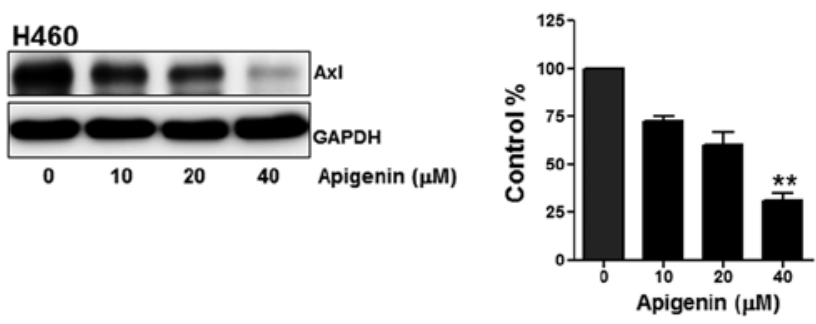

C

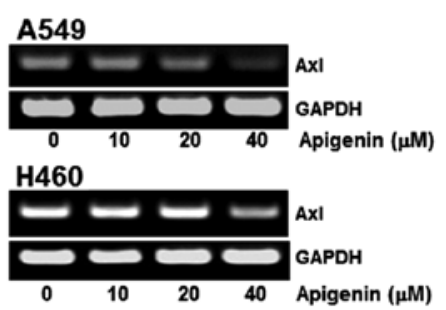

D
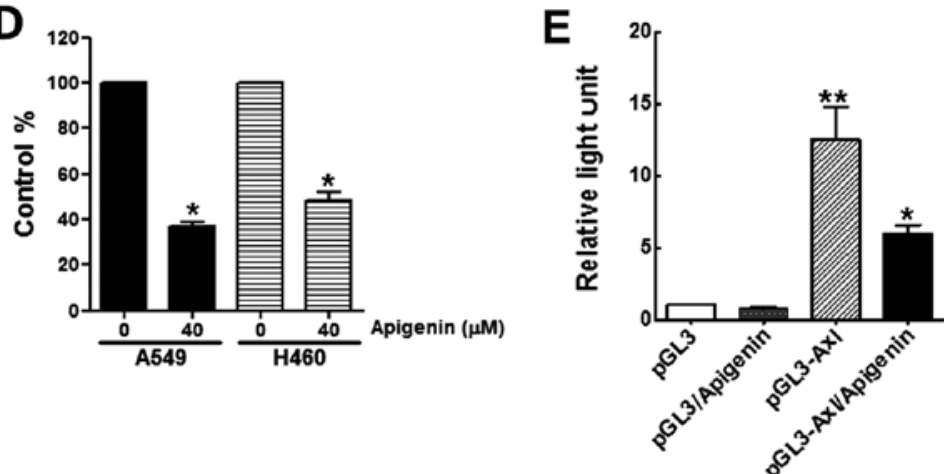

Figure 1. Apigenin reduces Axl expression in human lung cancer cells. The A549 and H460 cells were treated with the indicated concentrations of apigenin for $24 \mathrm{~h}$. (A and B) The protein level of Axl was determined by western blot analysis in order to assess the effects of apigenin on its expression. GAPDH was used as a loading control. Results are from 3 independent experiments. ${ }^{*} \mathrm{P}<0.05$, apigenin-treated vs. untreated cells; ${ }^{* *} \mathrm{P}<0.001$, apigenin-treated vs. untreated cells. $(\mathrm{C})$ For RT-PCR, total RNA from the cells was isolated and used for the analysis of Axl mRNA expression. The level of Axl mRNA was normalized to that of GAPDH. The data shown are representative of 3 independent experiments. (D) qPCR (SYBR-Green) was performed to measure Axl mRNA expression in the A549 and H460 cells treated with apigenin for $24 \mathrm{~h}$. Each sample was performed in triplicate, and the Axl mRNA expression was calculated relative to GAPDH. The asterisks indicate the significant difference compared to the control value ( $\mathrm{P}<0.05$, apigenin-treated vs. untreated cells). (E) To determine $A x l$ promoter activity, the A549 cells $\left(3 \times 10^{3}\right.$ cells/dish) were transfected with pGL3 or pGL3-Axl, Axl promoter-luciferase plasmid, using Lipofectamine 2000. The cells were then incubated with apigenin and total cell lysates were used to measure luciferase activity. The data shown are representative of at least 3 independent experiments. Data are expressed as the means \pm SD of triplicate samples conducted in 3 independent experiments. The asterisks indicate the significant difference compared to the control value ( $\mathrm{P}<0.05$, pGL3-Axl/apigenin vs. pGL3; and ${ }^{* *} \mathrm{P}<0.001$, pGL3-Axl vs. pGL3).

and antisense, 5'-UCAGUGUGUUCUCCAAAUCUU-3'), as previously described (30), or control siRNA. The cells were harvested for 24 and $48 \mathrm{~h}$ after transfection and used to evaluate protein expression, as well as in cell proliferation and colony formation assays.

Statistical analysis. Data are expressed as the means \pm SD of triplicate samples or at least 3 independent experiments. To determine statistical significance, the Student's t-test was used with a p-value threshold of $<0.05$.

\section{Results}

Apigenin suppresses Axl expression in human lung cancer cells. To determine the effects of apigenin on Axl expression, the human lung cancer cells, A549 and H460, were incubated with 10,20 , or $40 \mu \mathrm{M}$ of apigenin for $24 \mathrm{~h}$ and subsequently, Axl protein expression was measured. As shown in Fig. 1A and $\mathrm{B}$, the results from western blot analysis revealed that treatment with apigenin induced a dose-dependent decrease in the protein expression of Axl in both cell lines. More specifically, when the cells were exposed to $40 \mu \mathrm{M}$ apigenin for $24 \mathrm{~h}$, the Axl protein levels in the A549 and H460 cells were diminished to 57 and $35 \%$ compared with the untreated cells, respectively.

The downregulation of Axl expression in the apigenintreated cells was further confirmed by RT-PCR and a promoter activity test. The results from RT-PCR revealed that in both cells lines, the mRNA levels of Axl were decreased following treatment with apigenin (Fig. 1C); these results were consistent with those from western blot analysis. Additionally, the results from qPCR revealed that the Axl mRNA levels in the A549 and $\mathrm{H} 460$ cells treated with $40 \mu \mathrm{M}$ apigenin for $24 \mathrm{~h}$ were reduced to 37 and $48 \%$ compared with the untreated cells, respectively (Fig. 1D).

To determine the effects of apigenin on the transcription of the $A x l$ gene, $A x l$ promoter activity was measured using luciferase reporter plasmid under the control of the human Axl promoter plasmid, pGL3-Axl. A549 cells were transfected with pGL3-Axl and then incubated with $40 \mu \mathrm{M}$ apigenin for $24 \mathrm{~h}$. As illustrated in Fig. 1E, luciferase activity significantly declined following treatment with apigenin. The results of RT-PCR as well as those from the promoter activity test indicated that apigenin suppressed Axl expression in the lung cancer cells at the transcriptional level.

Apigenin-mediated downregulation of Axl is responsible for its anti-proliferative effects on human lung cancer cells. Since Axl has been known to transduce cell survival, growth and proliferation $(19,20,25,27,31)$, we wished to determine whether the downregulation of Axl by apigenin affects lung cancer cell viability. The cells were incubated with $10,20,40 \mu \mathrm{M}$ of apigenin for $24 \mathrm{~h}$, and the number of viable cells was then counted. As shown in Fig. 2A, treatment with apigenin reduced cell viability in a dose-dependent manner. Following 


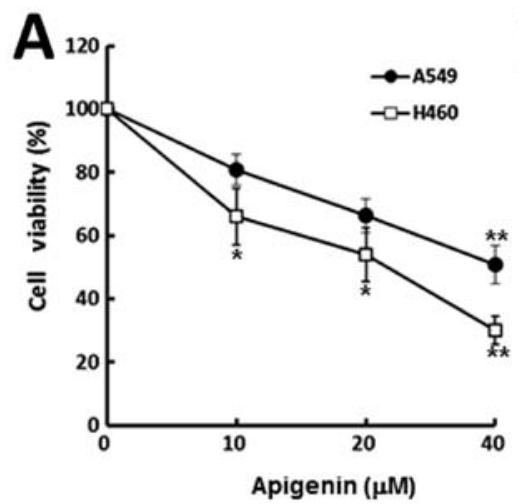

$B_{\text {A549 }}$
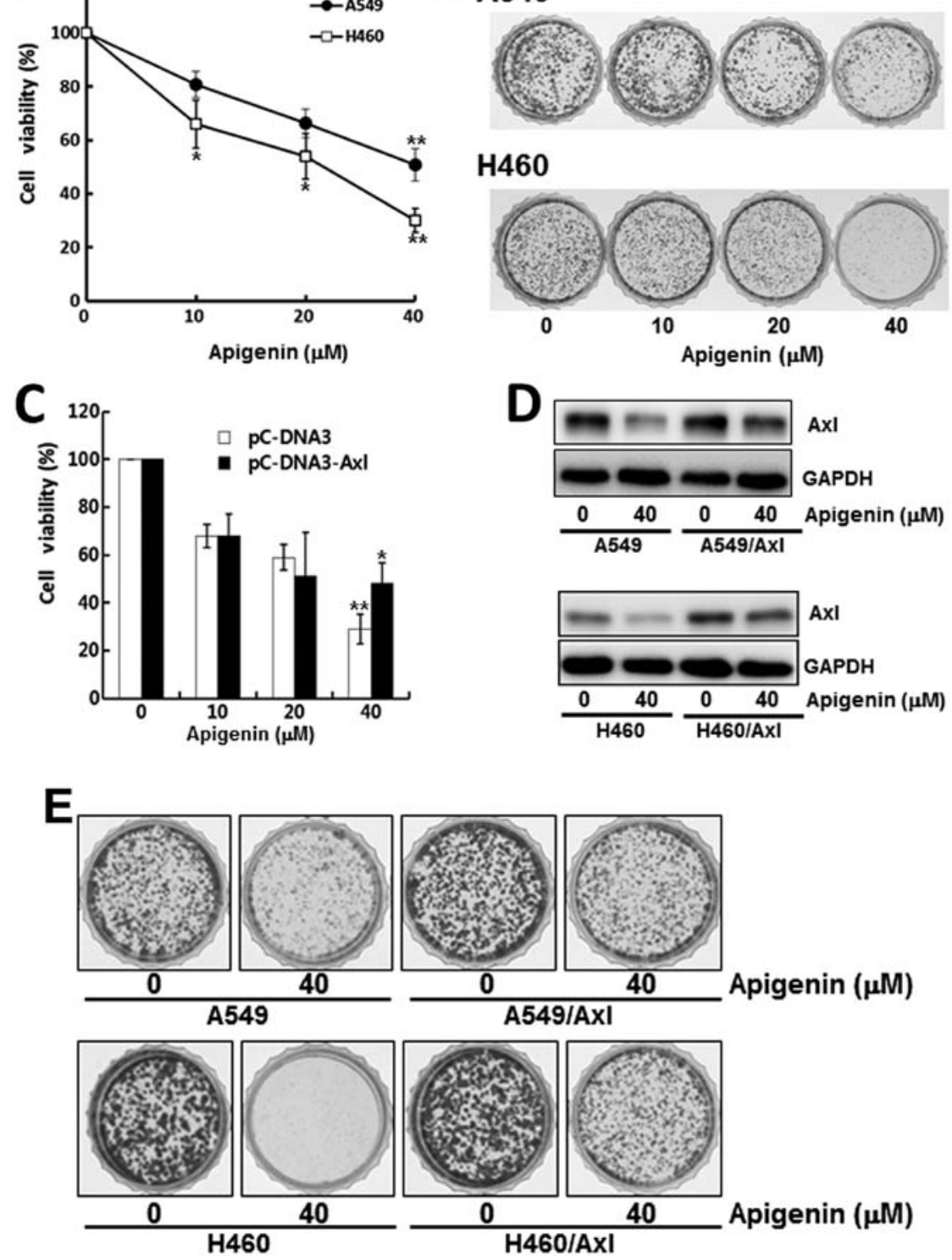

Figure 2. The apigenin-mediated downregulation of Axl is responsible for its anti-proliferative effects on human lung cancer cells. (A) Both A549 and H460 cells $\left(1 \times 10^{3}\right.$ cells/well) were seeded into 96-well plates, and the indicated concentrations of apigenin were then added to each well followed by incubation for $24 \mathrm{~h}$. Cell proliferation was determined by CCK- 8 assay. Data are expressed as the means \pm SD from 3 independent experiments. Data are expressed as the means \pm SD of triplicate samples conducted in 3 independent experiments. The asterisks indicate the significant difference compared to the control value ("P<0.05, 10 or $20 \mu \mathrm{M}$ apigenin-treated $\mathrm{H} 460$ cells vs. untreated $\mathrm{H} 460$ cells; and ${ }^{* *} \mathrm{P}<0.001,40 \mu \mathrm{M}$ apigenin-treated cells vs. untreated cells). (B) Cells ( $2 \times 10^{3}$ cells) were seeded into $35-\mathrm{mm}$ dishes and allowed to grow for 7-10 days until colonies were formed. The colonies were visualized by Crystal violet staining. The data shown are representative of at least 3 independent experiments. (C) A549 cells were transfected with pcDNA3 or pcDNA3-Axl plasmid and then incubated with the indicated concentrations of apigenin for $24 \mathrm{~h}$. Cell proliferation was determined by CCK- 8 assay. Data are expressed as the means \pm SD from 3 independent experiments. The asterisks indicate the significant difference compared to the control value ( ${ }^{*} \mathrm{P}<0.05,40 \mu \mathrm{M}$ apigenin-treated pC-DNA3-Axl cells vs. untreated pC-DNA3-Axl cells; and ${ }^{* *} \mathrm{P}<0.001,40 \mu \mathrm{M}$ apigenin-treated pC-DNA3 cells vs. untreated pC-DNA3 cells). (D) A549/Axl and H460/Axl cells were treated with apigenin for $24 \mathrm{~h}$. The total cell lysates were prepared and the Axl protein level was determined by western blot analysis. (E) Colony formation assay was performed with the A549/ Axl and H460/Axl cells in the presence or absence of apigenin. Colonies formed during 10 days of culture were visualized by Crystal violet staining.

treatment of the A549 and $\mathrm{H} 460$ cells with $40 \mu \mathrm{M}$ apigenin, only 49 and $37 \%$ of the cells survived, respectively.

The anti-proliferative effects of apigenin on the lung cancer cells were further confirmed by colony formation assay. The cells were cultured for 10 days in the presence of $10,20,40 \mu \mathrm{M}$ of apigenin. The exposure of the cells to apigenin resulted in a dose-dependent inhibition of colony formation (Fig. 2B). More specifically, the $\mathrm{H} 460$ cells failed to grow into a colony under $40 \mu \mathrm{M}$ apigenin, demonstrating the cytotoxic effects of apigenin on lung cancer cells.
To verify the involvement of Axl in the apigenin-mediated inhibition of cell proliferation, we examined whether the overexpression of Axl has an impact on the anti-proliferative effects of apigenin. The Axl-expressing construct, pcDNA3-Axl, was transiently transfected into the A549 cells and the cells were then cultured with or without apigenin for $24 \mathrm{~h}$. Compared to the control cells transfected with a pcDNA3 empty vector, the cells transfected with the pcDNA3-Axl plasmid were found to be slightly less sensitive to apigenin treatment (Fig. 2C), indicating that the overexpression of Axl protein diminisehd 

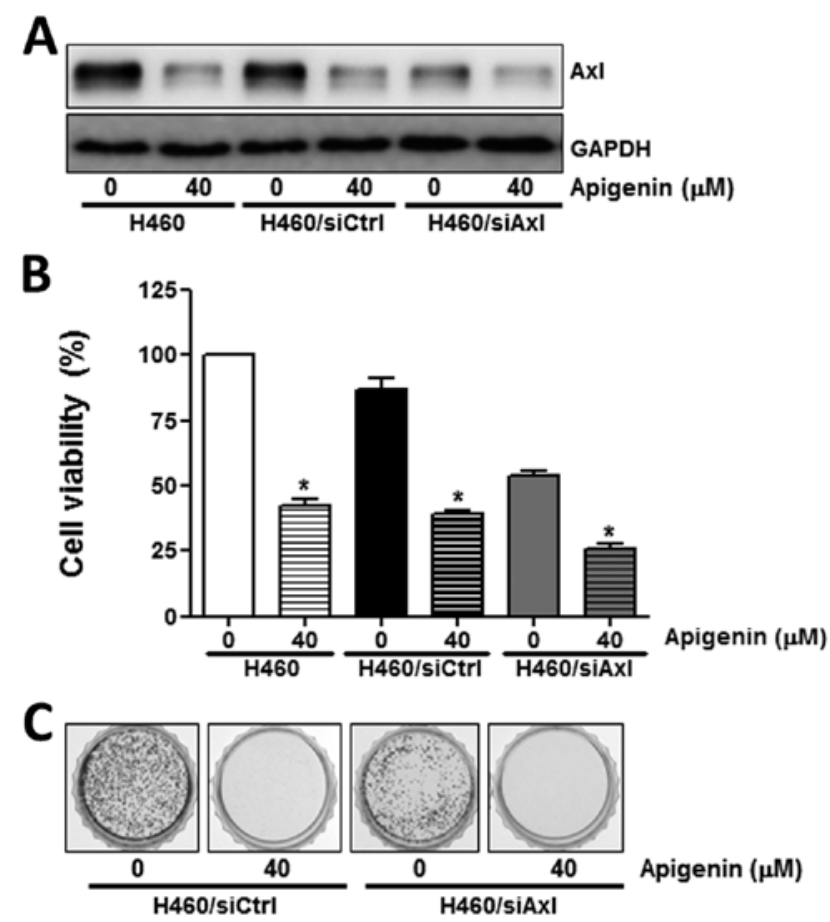

Figure 3. Inhibition of Axl augments the anti-proliferative effects of apigenin on human lung cancer cells. $\mathrm{H} 460$ cells $\left(3 \times 10^{3}\right.$ cells) were transfected with control siRNA (siCtrl) or Axl-specific siRNA (siAxl). (A) Cells were harvested $48 \mathrm{~h}$ post-transfection, total cell lysates were prepared, and the Axl protein level was determined by western blot analysis. (B) H460, H460/siCtrl and $\mathrm{H} 460 / \mathrm{siAxl}$ cells $\left(1 \times 10^{3}\right.$ cells/well) were plated onto 96-well plates and the indicated concentrations of apigenin were added to each well followed by incubation for $24 \mathrm{~h}$. Cell proliferation was determined by CCK-8 assay. Data are expressed as the means \pm SD from 3 independent experiments. The asterisks indicate the significant difference compared to the control value ( ${ }^{*} \mathrm{P}<0.05$, $40 \mu \mathrm{M}$ apigenin-treated cells vs. untreated cells) (C) $\mathrm{H} 460 / \mathrm{siCtrl}$ and $\mathrm{H} 460 /$ siAxl cells $\left(2 \times 10^{3}\right.$ cells) were grown for 7-10 days until they formed colonies. The colonies were visualized by Crystal violet staining.

the anti-proliferative effects of apigenin in the cells transfected with the pcDNA3-Axl plasmid.

Subsequently, we established Axl-overexpressing stable cell lines, A549/Axl and H460/Axl, and observed the effects of apigenin on cell proliferation. Western blot analysis revealed that the Axl protein level in the Axl-overexpressing cells was higher than in their parental cells, even following treatment with apigenin (Fig. 2D). Colony formation assay also revealed that both the A549/Axl and H460/Axl cells formed more colonies and were less affected by treatment with apigenin (Fig. 2E); these results are consistent with those from western blot analysis.

To further demonstrate the role of Axl in the anti-proliferative effects of apigenin, its expression was inhibited by specific siRNA. In contrast to the control siRNA, siCtrl, the Axl targetingsiRNA, siAxl, induced a significant decrease in Axl expression (Fig. 3A), resulting in a reduction in cell proliferation (Fig. 3B), as well as in colony formation (Fig. 3C). Taken together, these results suggest that Axl protein expression correlates with cell proliferation and that the anti-proliferative effects of apigenin are mediated by the modulation of Axl expression.

Apigenin-induced downregulation of Axl expression facilitates the induction of $p 21$ and reduction of XIAP expression. To
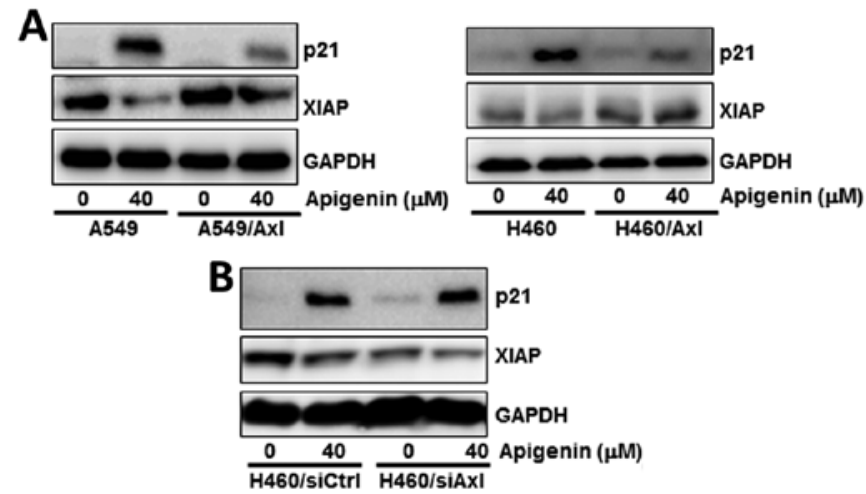

Figure 4. The apigenin-induced downregulation of Axl expression facilitates the induction of p21 and the reduction of XIAP expression. (A) A549 and $\mathrm{H} 460$ cells $\left(3 \times 10^{3}\right.$ cells) were treated with apigenin for $24 \mathrm{~h}$. Following treatment, total cell lysates were prepared, and western blot analysis was conducted to determine the p21 and XIAP protein levels. GAPDH was also detected as a loading control. The data shown are representative of 3 independent experiments. (B) $\mathrm{H} 460$ cells $\left(3 \times 10^{3}\right.$ cells) were transfected with siCtrl or siAxl. Subsequently, $24 \mathrm{~h}$ post-transfection, the cells were treated with apigenin for $24 \mathrm{~h}$. Following treatment, total cell lysates were prepared and western blot analysis was conducted to determine the p21 and XIAP protein levels. GAPDH was also detected as a loading control.

elucidate the molecular mechanisms by which the apigeninmediated downregulation of Axl expression results in the inhibition of cell proliferation, we examined the effects of apigenin on several molecules related to cell cycle regulation and apoptosis. The A549 and H460 cells were treated with $40 \mu \mathrm{M}$ apigenin for $24 \mathrm{~h}$. The results from western bolt analysis revealed that treatment with apigenin increased the levels of the cyclin-dependent kinase inhibitor, $\mathrm{p} 21$, which induces cell cycle arrest, but decreased the levels of XIAP, which inhibits apoptosis (Fig. 4A and B). These effects (the induction of p21 and the decrease in XIAP expressino) upon treatment with apigenin were attenuated or augmented in the Axl-overexpressing A549 and H460 cells (Fig. 4A) or in the siAxl-transfected H460 cells (Fig. 4B), respectively. These data indicate that the apigenin-induced downregulation of Axl expression is a prerequisite for the subsequent increase or reduction in $\mathrm{p} 21$ and XIAP expression.

\section{Discussion}

The first observation by Birt et al demonstrated that apigenin is an anti-mutagenic and anti-promotion bioflavonoid based on its inhibitory effects on ornithine decarboxylase, which plays an important role in tumor promotion (32). Subsequently, a number of other studies further confirmed its antioxidant, anti-inflammatory, anti-angiogenic and anti-proliferative activities, which revealed various targets of apigenin simultaneously. For instance, apigenin has been shown to suppress lipopolysaccharide (LPS)-induced cyclooxygenase-2 and nitric oxide synthase-2 expression (33) and TNF- $\alpha$ induced nuclear factor- $\mathrm{\kappa B}$ activation (34), which are major mediators for eliciting inflammation. In addition, apigenin has been verified as an effective inhibitor of the p34 (cdc2) kinase, which increases p53 stability (35), and a good inducer of the p21 and Apaf-1 proteins, which are the main players for cell cycle arrest and the induction of apoptosis $(36,37)$. Based on these data, apigenin 
has evoked particular interest in its potential as a chemopreventive and chemotherapeutic agent.

In this study, we found a new target of apigenin, Axl RTK, which is a member of the TAM RTK subfamily and has been reported to be overexpressed in a various types of cancer and to have an oncogenic potential $(18,23,24)$. The exposure of NSCLC cells (A549 and H460) to apigenin resulted in a decrease in Axl mRNA and protein expression (Fig. 1A-D). Furthermore, $A x l$ promoter activity was also reduced following treatment with apigenin (Fig. 1E), indicating that apigenin suppresses Axl expression at the transcriptional level.

Specific targeting of Axl with RNAi or monoclonal antibodies, which causes the downregulation of Axl expression, has been reported to reduce the proliferation of NSCLC cells in vitro and in vivo (using tumor xenografts) $(38,39)$. In addition, the overexpression and/or activation of Axl has been shown to be a mechanism that confers acquired resistance to various chemotherapeutic drugs, including gefitinib or erlotinib that are EGF receptor (EGFR) inhibitors in NSCLC (40-42) and head and neck cancer (31), imatinib that is a TKI in chronic myelogenous leukemia (43) and gastrointestinal stromal tumors (44), and tumor necrosis factor-related apoptosisinducing ligand in esophageal adenocarcinoma (45). Therefore, we examined whether the inhibition of Axl expression by apigenin affects the proliferation of NSCLC cells. In agreement with previous studies, we also found that treatment with apigenin inhibited the proliferation and clonogenic ability of the A549 and H460 cells in a dose-dependent manner (Fig. 2A and $\mathrm{B}$ ). Furthermore, the anti-proliferative effects of apigenin were decreased or augmented by the induction (Fig. 2C and $\mathrm{E}$ ) or inhibition of Axl expression (Fig. 3B), respectively. We also found that the ectopic expression of Axl diminished the apigenin-induced increase in $\mathrm{p} 21$ protein expression and the reduction in XIAP expression (Fig. 4A), which facilitates cell cycle arrest and apoptosis, respectively. By contrast, the inhibition of Axl expression using specific siRNA was found to augment both the induction of $\mathrm{p} 21$ and the reduction of XIAP upon treatment with apigenin (Fig. 4B). These results suggest that the Axl protein level correlates with cell proliferation, and the anti-proliferative effects of apigenin are mediated by the modulation of Axl expression.

In conclusion, our observations indicate that the treatment of NSCLC cells with apigenin suppresses Axl expression at the transcriptional level, which subsequently induces the inhibition of cell proliferation through the induction of cell cycle arrest and/or apoptosis. These results suggest that Axl is a novel target of apigenin through which it exerts its anti-proliferative effects on cancer cells.

\section{Acknowledgements}

This study was supported by the Basic Science Research Program through the, National Research Foundation of Korea (NRF) funded by the Ministry of Education, Science and Technology (grant no. 2006-2005303).

\section{References}

1. Liu C, Tu FX and Chen X: Neuroprotective effects of apigenin on acute transient focal cerebral ischemia-reperfusion injury in rats. Zhong Yao Cai 31: 870-873, 2008 (In Chinese).
2. Svehliková V,BennettRN,MellonFA, etal: Isolation,identification and stability of acylated derivatives of apigenin 7-O-glucoside from chamomile (Chamomilla recutita [L.] Rauschert). Phytochemistry 65: 2323-2332, 2004.

3. Birt DF, Hendrich S and Wang W: Dietary agents in cancer prevention: flavonoids and isoflavonoids. Pharmacol Ther 90: 157-177, 2001.

4. Surh YJ: Cancer chemoprevention with dietary phytochemicals. Nat Rev Cancer 3: 768-780, 2003.

5. Manach C, Scalbert A, Morand C, Rémésy C and Jiménez L: Polyphenols: food sources and bioavailability. Am J Clin Nutr 79: 727-747, 2004.

6. Yang CS, Landau JM, Huang MT and Newmark HL: Inhibition of carcinogenesis by dietary polyphenolic compounds. Annu Rev Nutr 21: 381-406, 2001.

7. Bevilacqua L, Buiarelli F, Coccioli $\mathrm{F}$ and Jasionowska R: Identification of compounds in wine by HPLC-tandem mass spectrometry. Ann Chim 94: 679-689, 2004.

8. Zheng PW, Chiang LC and Lin CC: Apigenin induced apoptosis through p53-dependent pathway in human cervical carcinoma cells. Life Sci 76: 1367-1379, 2005.

9. Lu HF, Chie YJ, Yang MS, et al: Apigenin induces apoptosis in human lung cancer $\mathrm{H} 460$ cells through caspase- and mitochondriadependent pathways. Hum Exp Toxicol 30: 1053-1061, 2011.

10. Zhong Y, Krisanapun C, Lee SH, et al: Molecular targets of apigenin in colorectal cancer cells: involvement of p21, NAG-1 and p53. Eur J Cancer 46: 3365-3374, 2010.

11. Ruela-de-Sousa RR, Fuhler GM, Blom N, Ferreira CV, Aoyama H and Peppelenbosch MP: Cytotoxicity of apigenin on leukemia cell lines: implications for prevention and therapy. Cell Death Dis 1: e19, 2010.

12. Li ZD, Hu XW, Wang YT and Fang J: Apigenin inhibits proliferation of ovarian cancer A2780 cells through Id1. FEBS Lett 583: 1999-2003, 2009.

13. Shukla S, MacLennan GT, Flask CA, et al: Blockade of beta-catenin signaling by plant flavonoid apigenin suppresses prostate carcinogenesis in TRAMP mice. Cancer Res 67: 6925-6935, 2007

14. Liu LZ, Fang J, Zhou Q, Hu X, Shi X and Jiang BH: Apigenin inhibits expression of vascular endothelial growth factor and angiogenesis in human lung cancer cells: implication of chemoprevention of lung cancer. Mol Pharmacol 68: 635-643, 2005.

15. Fang J, Xia C, Cao Z, Zheng JZ, Reed E and Jiang BH: Apigenin inhibits VEGF and HIF-1 expression via PI3K/AKT/p70S6K1 and HDM2/p53 pathways. FASEB J 19: 342-353, 2005.

16. Mirzoeva S, Kim ND, Chiu K, Franzen CA, Bergan RC and Pelling JC: Inhibition of HIF-1 alpha and VEGF expression by the chemopreventive bioflavonoid apigenin is accompanied by Akt inhibition in human prostate carcinoma PC3-M cells. Mol Carcinog 47: 686-700, 2008.

17. Liu E, Hjelle B, Bishop JM: Transforming genes in chronic myelogenous leukemia. Proc Natl Acad Sci USA 85: 1952-1956, 1988.

18. O'Bryan JP, Frye RA, Cogswell PC, et al: axl, a transforming gene isolated from primary human myeloid leukemia cells, encodes a novel receptor tyrosine kinase. Mol Cell Biol 11: 5016-5031, 1991.

19. Rochlitz C, Lohri A, Bacchi M, et al: Axl expression is associated with adverse prognosis and with expression of Bcl-2 and CD34 in de novo acute myeloid leukemia (AML): results from a multicenter trial of the Swiss Group for Clinical Cancer Research (SAKK). Leukemia 13: 1352-1358, 1999.

20. Berclaz G, Altermatt HJ, Rohrbach V, Kieffer I, Dreher E and Andres AC: Estrogen dependent expression of the receptor tyrosine kinase axl in normal and malignant human breast. Ann Oncol 12: 819-824, 2001.

21. Craven RJ, Xu LH, Weiner TM, et al: Receptor tyrosine kinases expressed in metastatic colon cancer. Int J Cancer 60: 791-797, 1995.

22. Ito T, Ito M, Naito S, et al: Expression of the Axl receptor tyrosine kinase in human thyroid carcinoma. Thyroid 9: 563-567, 1999.

23. Nemoto T, Ohashi K, Akashi T, Johnson JD and Hirokawa K: Overexpression of protein tyrosine kinases in human esophageal cancer. Pathobiology 65: 195-203, 1997.

24. Shieh YS, Lai CY, Kao YR, et al: Expression of axl in lung adenocarcinoma and correlation with tumor progression. Neoplasia 7: 1058-1064, 2005.

25. Hutterer M, Knyazev P, Abate A, et al: Axl and growth arrest-specific gene 6 are frequently overexpressed in human gliomas and predict poor prognosis in patients with glioblastoma multiforme. Clin Cancer Res 14: 130-138, 2008. 
26. Sun WS, Fujimoto J and Tamaya T: Coexpression of growth arrest-specific gene 6 and receptor tyrosine kinases Axl and Sky in human uterine endometrial cancers. Ann Oncol 14: 898-906, 2003.

27. Gustafsson A, Martuszewska D, Johansson M, et al: Differential expression of Axl and Gas6 in renal cell carcinoma reflecting tumor advancement and survival. Clin Cancer Res 15: 4742-4749, 2009.

28. Byers LA, Diao L, Wang J, et al: An epithelial-mesenchymal transition gene signature predicts resistance to EGFR and PI3K inhibitors and identifies Axl as a therapeutic target for overcoming EGFR inhibitor resistance. Clin Cancer Res 19: 279-290, 2013.

29. Liu L, Greger J, Shi H, et al: Novel mechanism of lapatinib resistance in HER2-positive breast tumor cells: activation of AXL. Cancer Res 69: 6871-6878, 2009.

30. Holland SJ, Powell MJ, Franci C, et al: Multiple roles for the receptor tyrosine kinase axl in tumor formation. Cancer Res 65: 9294-9303, 2005.

31. Giles KM, Kalinowski FC, Candy PA, et al: Axl mediates acquired resistance of head and neck cancer cells to the epidermal growth factor receptor inhibitor erlotinib. Mol Cancer Ther 12 : 2541-2558, 2013.

32. Birt DF, Walker B, Tibbels MG and Bresnick E: Anti-mutagenesis and anti-promotion by apigenin, robinetin and indole-3-carbinol. Carcinogenesis 7: 959-963, 1986.

33. Liang YC, Huang YT, Tsai SH, Lin-Shiau SY, Chen CF and Lin JK: Suppression of inducible cyclooxygenase and inducible nitric oxide synthase by apigenin and related flavonoids in mouse macrophages. Carcinogenesis 20: 1945-1952, 1999.

34. Choi JS, Choi YJ, Park SH, Kang JS and Kang YH: Flavones mitigate tumor necrosis factor-alpha-induced adhesion molecule upregulation in cultured human endothelial cells: role of nuclear factor-kappa B. J Nutr 134: 1013-1019, 2004.
35. Plaumann B, Fritsche M, Rimpler H, Brandner G and Hess RD: Flavonoids activate wild-type p53. Oncogene 13: 1605-1614, 1996.

36. Lepley DM and Pelling JC: Induction of p21/WAF1 and G1 cell-cycle arrest by the chemopreventive agent apigenin. Mol Carcinog 19: 74-82, 1997.

37. Shukla S and Gupta S: Molecular mechanisms for apigenin-induced cell-cycle arrest and apoptosis of hormone refractory human prostate carcinoma DU145 cells. Mol Carcinog 39: 114-126, 2004.

38. Li Y, Ye X, Tan C, et al: Axl as a potential therapeutic target in cancer: role of Axl in tumor growth, metastasis and angiogenesis. Oncogene 28: 3442-3455, 2009.

39. Ye X, Li Y, Stawicki S, et al: An anti-Axl monoclonal antibody attenuates xenograft tumor growth and enhances the effect of multiple anticancer therapies. Oncogene 29: 5254-5264, 2010.

40. Gusenbauer S, Vlaicu P and Ullrich A: HGF induces novel EGFR functions involved in resistance formation to tyrosine kinase inhibitors. Oncogene 32: 3846-3856, 2013.

41. Zhang Z, Lee JC, Lin L, et al: Activation of the AXL kinase causes resistance to EGFR-targeted therapy in lung cancer. Nat Genet 44: 852-860, 2012.

42. Postel-Vinay S and Ashworth A: AXL and acquired resistance to EGFR inhibitors. Nat Genet 44: 835-836, 2012.

43. Dufies M, Jacquel A, Belhacene N, et al: Mechanisms of AXL overexpression and function in Imatinib-resistant chronic myeloid leukemia cells. Oncotarget 2: 874-885, 2011.

44. Mahadevan D, Cooke L, Riley C, et al: A novel tyrosine kinase switch is a mechanism of imatinib resistance in gastrointestinal stromal tumors. Oncogene 26: 3909-3919, 2007.

45. Hong $\mathrm{J}$ and Belkhiri A: AXL mediates TRAIL resistance in esophageal adenocarcinoma. Neoplasia 15: 296-304, 2013. 